\title{
Modeling of weir height drop on the slope of the open channel hydraulic jump
}

\author{
Jerome Godwin Egbe $1,{ }^{*}$ and Jonah Chukwuemeka Agunwamba ${ }^{2}$ \\ ${ }^{1}$ Department of Civil Engineering, Cross River University of Technology, Calabar-Nigeria. \\ 2 Department of Civil Engineering, University of Nigeria, Nsukka-Nigeria.
}

Publication history: Received on 24 September 2020; revised on 08 October 2020; accepted on 20 October 2020

Article DOI: https://doi.org/10.30574/wjaets.2020.1.1.0013

\begin{abstract}
The model design was developed for the alignment and it was utilized to test for various geometrics and stream conditions searching for a low and incentive for RMSE and the response variable. Also, during the alignment half of the exploratory information was set to their coefficients, and the staying set of information was similarly be utilized for confirmation purposes. Utilizing around thirty out of the fifty informational collections created in the research facility dependent on relapse investigation was applied to the non-direct model to decide the constants. The staying twenty informational collections from research centre analyses were utilized for check of the model. The absence of the fittest was utilized likewise to check the request for the proposed relapse model utilizing the water profundity as the response variable. The Froude numbers from the post-pressure driven hop segment from 0.37 to $0.41\left(0.37<\mathrm{Fr}_{3}<0.41\right)$, likewise showing that the streams are subcritical. The Froude numbers from the post-pressure driven hop area inside 0.37 to $0.41\left(0.37<\mathrm{Fr}_{3}<0.41\right)$, this shows the streams are subcritical. The connection between sequent profundity proportion $\mathrm{y}_{3} / / \mathrm{y}_{2}$ and speed proportion $\mathrm{V}_{2} / \mathrm{V}_{3}$ is around $-5024+1.485 \mathrm{Fr}_{2}$ with $\mathrm{R}^{2}=0.9957$ showing that as the sequent profundity proportion and speed proportion expands the inflow Froude number Fr $_{2}$ additionally increments, the hydraulic jump extended from - 0.001 to 0.001 which gives some vitality progression with an expansion in the pace of release through the flume. The upstream of the flume, the Froude numbers go from 0.038 to $0.052\left(0.038<\mathrm{Fr}_{1}<0.52\right)$, demonstrating that the streams were subcritical and less harm to the channel.
\end{abstract}

Keywords: Alignment; Model design; Sequent Profundity; Hydraulic Jump.

\section{Introduction}

Hydraulic jump has several applications in water resources engineering, especially in the design of hydraulic structures. In erosion and flood control works, there is often the need to dissipate energy to protect the hydraulic structures downstream. In such cases, a hydraulic jump could be used to dissipate the energy. However, the jump characteristics need to be determined correctly to design the channel stretch where the jump occurs. If the location is adjudged incorrectly, the channel sidewall to contain the jump may be terminated too abruptly or more concretely wasted. The parameters include the length, the height, and location of the jump [1], [2]. As recently portrayed, the water driven bounce assumes a basic function in liquid channels. For instance, a substance sanitization point ought to be developed just before the toe of the water-powered bounce. Consequently, the area of the bounce ought to be resolved first. In planning a stilling basin, the sequent depth of the jump ought to be known. The hydraulic jump can protect the banks of channels by slowing down the velocity of the continual high-velocity flow to avoid scouring in a channel. The free surface is an interface between two fluids of different thicknesses and on account of the air, the density of air is a lot slower than the density of water, furthermore, the weight is steady. Common channels, similar to waterways and brooks, coming about because of the geophysical cycles acting at the world's surface, without the fundamental interest of the human movement. The most reliable examinations on the weight-driven bounce, made by Bidone, were done in a slanting

\footnotetext{
* Corresponding author: Jerome Godwin Egbe

Department of Computer Science, Cross River University of Technology, Calabar -Nigeria.
} 
channel, [3], [4], and [5]. Accordingly, [6], started an expansive investigation program with slopes of 1 out of 6,1 out of 3 , and 1 out of 1 had settled the issues related to D-jump and B-bounce [17]. More so, [8] had introduced new enunciations for B-jump with Froude amounts of 2.4 to 7.4. Further, [9] had chosen the assortments of the mean streamflow with the water driven skip in inclining channels. Previously, [10] had investigated undular ricochets for completely created inflow conditions. Recently, [11] uncovered the negative bed slope of the stream bed diminished the sequent significance extent, and the positive bed incline extended the sequent significance extent. According to work done by [12] they examined the effect of bed brutality on the sequent significance extent and the roller length. In the same vain, [13] had developed the progressing propels in furious water-driven jumps. Similarly, [14] had investigated the streamflow of a rough water-driven ricochet in a horrendous rectangular channel bed. Similarly, [17] had inspected the characteristics of customary skip and B-bounces on smooth beds. Nevertheless [15] carried out a preliminaries studies to think about the instability of Froude numbers $(3.8<\mathrm{F} 1<8.5)$ and Reynold's number $(2.1 \times 104<\mathrm{R}<1.6 \times$ 105). As indicated by [16], the characterized weirs as a water-driven structure that speaks to a crucial constituent of the framework expecting a pertinent function as a daily existence supporting component for the populace. Furthermore, Egbe and Agunwamba [18] discuss the proposed design and derivation of mathematical procedure for modeling of hydraulic jump in a broad crested weir in an open channel flows. These structures appropriate water, wastewater, or other fluid substances upstream to serve different capacities, for example, flood control, water gracefully, water system, water level control, and so forth. As indicated by the Bureau of Reclamation of the United States, dams can be sorted dependent on three principle angles: use, water-driven plan, and material of development.

\section{Research Methodology}

The design of experiments (DOE) is a well-known methodology according to [19] which can be applied to physical experiments without any difficulty. This methodology was applied to the horizontal open channel flow. Since the Bernoulli energy equation and the continuity equation are applied in this study, the following assumptions are necessary for upstream flow before the jumps:

- The flow is steady.

- The flow is incompressible.

- The flow is frictionless.

- The flow is irrotational.

Accordingly, the outlet, the subcritical water stature that powers the pressure-driven bounce to happen inside the space (h2) must be forced. This variable must be gotten by iteratively testing different flow rates until the subsequent water is driven hop stays stable inside the channel. Ordinarily, subcritical water tallness and a hydrostatic profile ought to be forced at the outlet utilizing a Dirichlet water level limit condition. A barometrical limit condition is forced at the head of the channel to permit liquids to enter and leave the channel. This is accomplished by forcing an invalid Von Neumann condition to all factors aside from pressure, which is set to zero (environmental weight). Figure 1 sums up the model limit conditions and a portion of its most applicable factors to examine.

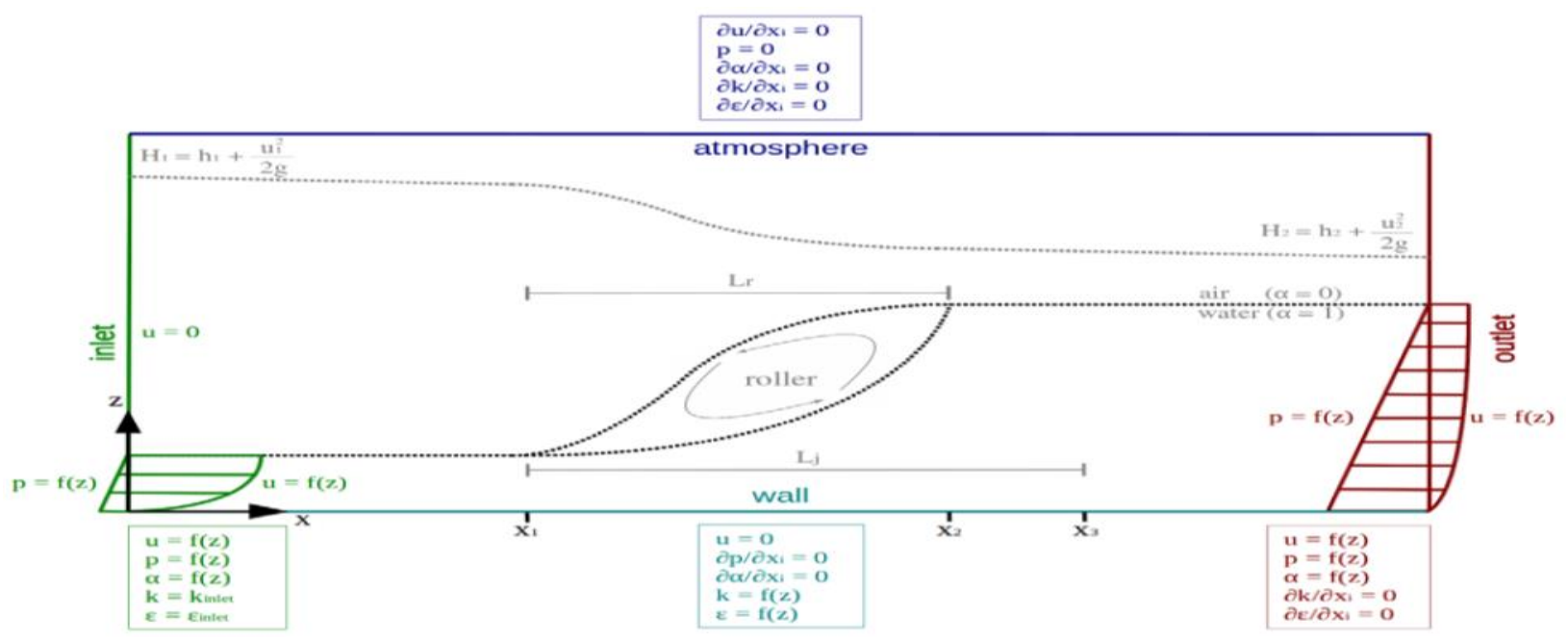


Figure 1 The boundary conditions used for the hydraulic jump model

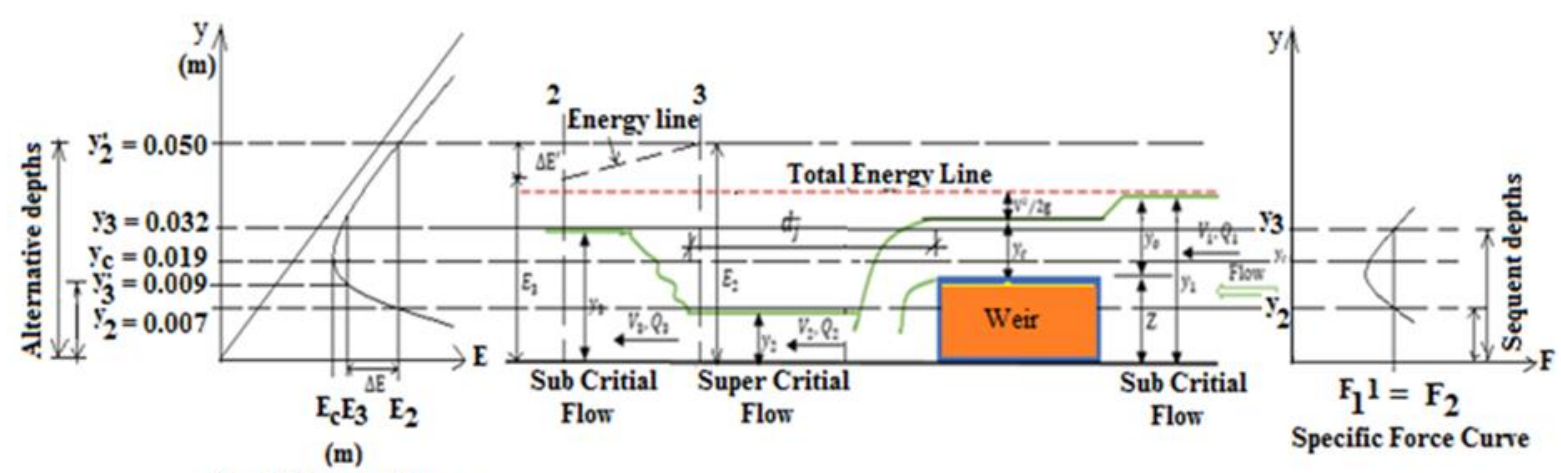

Specific Energy Curve

Figure 2 The Proposed design of specific energy and curves of the constricted flume [18]

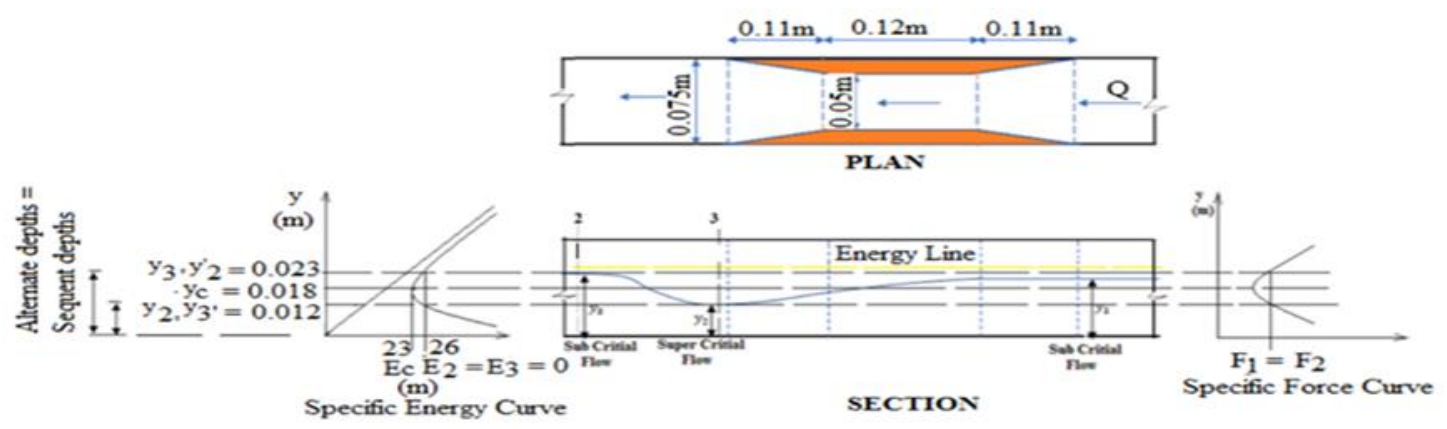

Figure 3 The Proposed Experimental Design of Test section of the channel

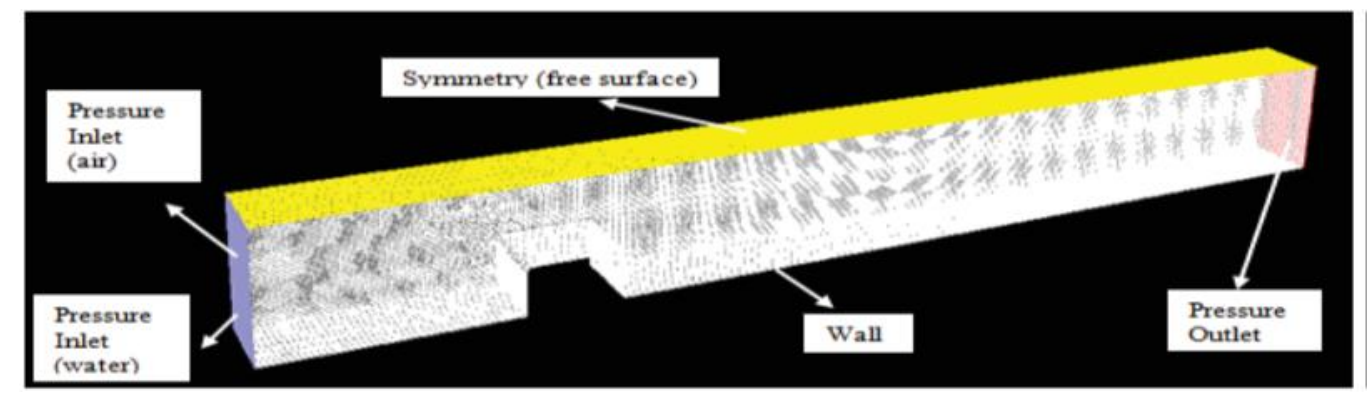

Figure 4 The photograph of a 3D view of the open channel

\subsection{Experimental Procedure}

The experimental examinations were carried out in a variable slant open channel pressure-driven (VSOCPD) which we remade and structured in the Civil Engineering Water Resources/Hydraulic Research Centre, of the Cross River University of Technology, Calabar. The materials that were utilized to revamp the VSOCPD is appeared in Figure 5, including the accompanying: cylindrical metal with a rectangular profile, $0.075 \mathrm{~cm}$ wide and $5 \mathrm{~m}$ long, to fabricate the base; pressure has driven jack to change the inclines of the VSOCPD; acrylic sheets to manufacture the dividers and the base of the channel; two tripods built with three bits of prepares of 3 inches $(80 \mathrm{~mm})$ width to help the heaviness of the channel; a volumetric tank that serves not just as "reference model" to approve $Q$ and as a store "water consumption" for the dissemination of the stream rate (Q) into the VSOCPD; 3 HP fuel siphon with 2 inches (50.8 mm) measurement of yield to drive water from the reservoir "water admission" to VSOCPD and to circle the stream in a shut framework.

We input four different flow rates (Q) through it. Every $Q$ had a discretionary increment and reduction of $Q$ to maintain a strategic distance from factual propensities in the length of the hop count, while the gate opening "a" stayed moderate. 
We assessed the stream rates $(Q)$ with the volumetric strategy, utilizing the dissemination tank of the VSOCPD which was recently aligned. The Manning " $n$ " used is 0.009 (acrylic), and different adjusted slopes. We measured the following variables directly in the experimental model: Length (L), major hydraulic depth $\left(y_{1}\right)$ and minor hydraulic depth $\left(y_{2}\right)$, which provided the data to calculate Froude's numbers: $F_{r 1}$ and $F_{r 2}$.

The detailed drawings of the experimental flume were drawn and the accessories were collected as depicted in Figure 5.

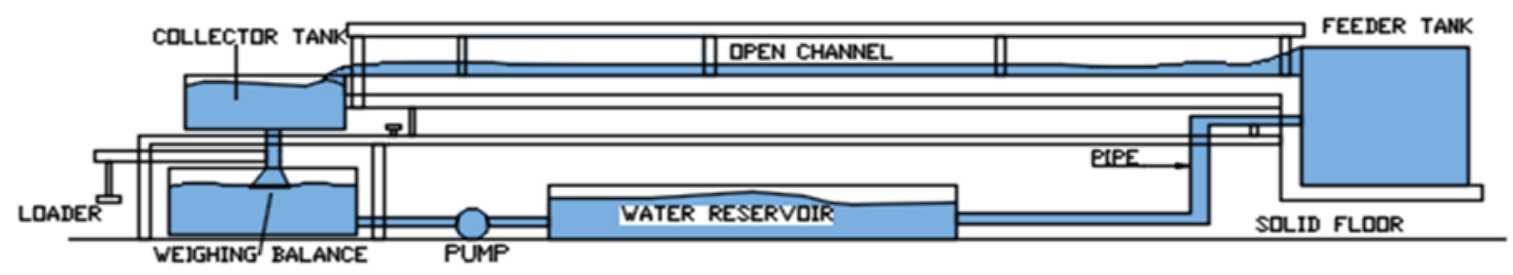

Figure 5 Experimental setup of the Flume

\subsection{Testing specimens for flume}

The weir specimens are 3 rectangular steel tablets $0.114 \mathrm{~m}(114 \mathrm{~mm})$ long, $0.075 \mathrm{~m}(75 \mathrm{~mm})$ wide, and $0.025 \mathrm{~m}(25$ $\mathrm{mm}$ ) in height, respectively. The flume specimens are 2 rectangular glass tablets, tapered at both ends, $0.34 \mathrm{~m}(340 \mathrm{~mm})$ long, $0.0125 \mathrm{~m}(12.5 \mathrm{~mm})$ thick, and $0.15 \mathrm{~m}(150 \mathrm{~mm})$ in height.

\subsection{The mathematical formulation of the weir}

Assuming no loss of head,

$\mathrm{H}_{\text {weir }}=\mathrm{U}_{\text {pstream; }} \quad$ where $=\mathrm{y}_{3}+\frac{\mathrm{v}_{3}^{2}}{2 \mathrm{~g}}$

\section{Notation}

$q=(Q / b)=$ discharge per unit width

$b=$ channel width

$Z_{\text {Weir }}=$ Weir depth (Tablet thickness)

$y c_{c a l}=$ Calculated critical depth for minimum energy obtained by $=2 / 3 y_{0}$

$y c_{\text {theory }}=$ Theoretical critical depth for minimum energy $=\sqrt[3]{\frac{(\mathbf{Q u} / \mathbf{b})^{2}}{\mathrm{~g}}}=\sqrt[3]{\frac{(\mathbf{q})^{2}}{\mathrm{~g}}}$

Froude number at any position $=\frac{V}{\sqrt{g h}}$

$\Delta \mathrm{E}=$ The loss of energy head due to the occurrence of the hydraulic jump,

$\Delta \mathrm{E}=\mathrm{E}_{1}-\mathrm{E}_{2}=\left(\mathrm{y}_{1}+\frac{\mathrm{v}_{1}^{2}}{2 \mathrm{~g}}\right)-\left(\mathrm{y}_{2}+\frac{\mathrm{v}_{2}^{2}}{2 \mathrm{~g}}\right)$,

$\mathrm{y}_{1}=$ Measured downstream jump depth

$y_{2}=y_{2, \text { theory }}=$ Theoretical downstream depth of jump $=\frac{y_{1}}{2}+\sqrt{\left(\frac{y_{1}^{2}}{4}+\frac{2 y_{1} v_{1}^{2}}{g}\right)}$, 
Average measured flow time, $\mathbf{t}_{\mathrm{av}}=\frac{\boldsymbol{t}_{1}+\boldsymbol{t}_{2}}{2}$,

Where:

$\mathrm{y}_{1}, v_{1}=$ Measured depth and velocity upstream of the jump,

$\mathrm{y}_{2}, v_{2}=$ Measured depth and velocity upstream of the jump,

$\mathrm{Q}_{\mathrm{d}}, Q_{u}=$ Measured discharge downstream and upstream of weir or flume, respectively $=\mathrm{A}_{\mathrm{i}} v_{i}$,

$\mathrm{A}_{1}, v_{i}=$ Sectional area perpendicular to flow direction and flow velocity,

$\mathrm{y}_{3}, v_{3}=$ Measured depth and velocity upstream of weir or flume,

$\mathrm{y}_{\mathrm{o}}=$ Measured water depth above the crest upstream of the weir (freeboard),

$\mathrm{y}_{\mathrm{c}, \exp }, \mathrm{y}_{\mathrm{c}, \text { theory }}, \mathrm{y}_{\mathrm{c}, \mathrm{cal}}=$ Measured, theoretical, and calculated critical depth above the weir crest, respectively.

\subsection{Dimensional Analysis}

The dimensional investigation approach is utilized to recognize the valuable parameter combinations, which requires dimensional consistency in the condition governing the process of interest. Nonetheless, the necessity for the dimensional consistency applies to conditions that have measurements in each term, it is constantly applied in manners that convert all the terms to dimensionless gatherings. A fundamental physical quantity is the combination of length, mass, and time (meant L, M, and T, separately). The Buckingham pi hypothesis is applied to provide the combinations between $\mathrm{N}$ amounts with $\mathrm{M}$ measurements. This hypothesis orchestrates the amounts as $\mathrm{N}-\mathrm{M}$ free dimensionless boundaries. Thusly, the useful connection must exist, [20].

Table 1The Dimensional Analysis Approach

\begin{tabular}{|l|l|l|l|l|l|l|l|l|l|l|l|}
\hline \multicolumn{10}{|c|}{ Dependable Variables } \\
\hline Variables & $\mathrm{K}_{1}$ & $\mathrm{~K}_{2}$ & $\mathrm{~K}_{3}$ & $\mathrm{~K}_{4}$ & $\mathrm{~K}_{5}$ & $\mathrm{~K}_{6}$ & $\mathrm{~K}_{7}$ & $\mathrm{~K}_{8}$ & $\mathrm{~K}_{9}$ & $\mathrm{~K}_{10}$ & \\
\hline & $\mathrm{Q}$ & $\mathrm{V}_{1}$ & $\mathrm{~L}_{\mathrm{d}}$ & $\mathrm{Y}_{\mathrm{c}}$ & $\mathrm{Y}_{1}$ & $\mathrm{Y}_{2}$ & $\mathrm{~L}_{\mathrm{j}}$ & $\mathrm{H}$ & $\mathrm{Z}$ & $\mathrm{G}$ & \\
\hline M & 0 & 0 & 0 & 0 & 0 & 0 & 0 & 0 & 0 & 0 & \\
\hline L & 2 & 1 & 1 & 1 & 1 & 1 & 1 & 1 & 1 & 1 & \\
\hline T & -1 & -1 & 0 & 0 & 0 & 0 & 0 & 0 & 0 & -2 & \\
\hline
\end{tabular}

$\pi=\rho_{1}^{c 1}, \rho_{2}^{c 2}, \rho_{1, \ldots,}^{c 3} \rho_{n}^{c n}$

These parameters contain three main variables such as $\mathrm{M}, \mathrm{L}$, and $\mathrm{T}$. If $\mathrm{P} 1$ has dimension

$M^{\alpha 1}, L^{\beta 1}, T^{\gamma 1}$, then the dimension of $\pi$ is as follows:

$\pi=\left(M^{\alpha 1} L^{\beta 1} T^{\gamma 1}\right)^{\mathrm{K} 1},\left(M^{\alpha 2} L^{\beta 2} T^{\gamma 2}\right)^{\mathrm{K} 2},\left(M^{\alpha n} L^{\beta n} T^{\gamma n}\right)^{\mathrm{Kn}}$,

For non- dimensional $\pi$

$$
\begin{aligned}
& \alpha_{2} K_{1}+\alpha_{2} K_{2}+\ldots \ldots+\alpha_{n} K_{2}=0 \\
& \beta_{2} K+\beta_{2} K_{2}+\ldots \ldots+\beta_{n} K_{2}=0 \\
& \gamma_{2} K_{1}+\gamma_{2} K_{2}+\ldots \ldots .+\gamma_{n} K_{2}=0
\end{aligned}
$$


Using Buckingham $\rho i$ method to analyze the hydraulic parameters involved in a weir structure and hydraulic jump as follows.

$\mathrm{q}=$ the flow discharge per unit width

$\mathrm{V}_{1}=$ the mean velocity of the upstream section

$\mathrm{L}_{\mathrm{d}}=$ drop length

$\mathrm{y}_{\mathrm{c}}=$ critical depth

$\mathrm{y}_{1}=$ the initial depth of the jump upstream

$\mathrm{y}_{2}=$ the sequent depth of the jump downstream

$\mathrm{Lj}=$ the length of the hydraulic jump

The formulation based on dimensional analysis

$\alpha_{1}=0$

$\beta_{1}=2 K_{1}+K_{2}+K_{3}+K_{4}+K_{5}+K_{6}+K_{7}+K_{8}+K_{9}+K_{10}$

$\gamma_{1}=-K_{1}-K_{2}-K_{10}$

By elimination of $K_{10}+K_{9}$

$2 K_{10}=-K_{1}-K$

$K_{10}=-0.5 K_{1}-0.5 K_{2}$

$K_{9}=-2 K_{1}-K_{2}-K_{3}-K_{4}-K_{5}-K_{6}-K_{7}-K_{8}-\left(-K_{1}-K_{2}\right)$

$K_{9}=-1.5 K_{1}-K_{2}-K_{3}-K_{4}-K_{5}-K_{6}-K_{7}-K_{8}$

\subsection{Applying Langhaar matrix in the above equations}

$\pi_{1}$, Variable had a relationship with $K_{1}, K_{9}$, and $K_{10}$, but it had no relationship with $K_{2}, K_{4}, K_{5}, K_{6}, K_{7}$ and $K_{8}$ respectively.

The $\pi_{2}$ variable had a relationship with $K_{1}, K_{3}, K_{4}, K_{5}, K_{6}, K_{7}$, and $K_{8}$,respectively.

The $\pi_{3}$ Variable had a relationship with $K_{3}, K_{9}, K_{10}$, but it had no relationship with $K_{1}, K_{2}, K_{4}, K_{6}, K_{7}$, and $K_{8}$,respectively. Similarly, variable $\pi_{4}, \pi_{5}, \pi_{6}, \pi_{7}$, and $\pi_{7}$ had a relationship with $K_{9}$.

The final analyses will be based on Langhaar Matrix which can be summarised by eight-dimensional relationships as follows:

$\pi_{1}=\frac{q^{2}}{g^{z 2}}, \quad \pi_{2}=\frac{V^{2}}{g \cdot Z}, \pi_{3}=\frac{L d}{Z}, \pi_{4}=\frac{y c}{Z}, \pi_{5}=\frac{y 1}{Z}, \pi_{6}=\frac{y 2}{Z}, \pi_{7}=\frac{L j}{Z}$, and $\pi_{8}=\frac{h}{Z}$

Table 2 Matrix formulation for the dimensional analysis

\begin{tabular}{|c|c|c|c|c|c|c|c|c|c|c|}
\hline \multirow{2}{*}{ Variables } & $k_{1}$ & $k_{2}$ & $k_{3}$ & $k_{4}$ & $k_{5}$ & $k_{6}$ & $k_{7}$ & $k_{8}$ & $k_{9}$ & $k_{10}$ \\
\hline & $q$ & $v_{1}$ & $L_{d}$ & $y_{c}$ & $y_{1}$ & $y_{2}$ & $L_{i}$ & $h$ & $z$ & $g$ \\
\hline$\pi_{1}$ & 1 & 0 & 0 & 0 & 0 & 0 & 0 & 0 & -1.5 & -0.5 \\
\hline$\pi_{2}$ & 0 & 1 & 0 & 0 & 0 & 0 & 0 & 0 & $-0,5$ & -0.5 \\
\hline$\pi_{3}$ & 0 & 0 & 1 & 0 & 0 & 0 & 0 & 0 & -1.0 & 0 \\
\hline$\pi_{4}$ & 0 & 0 & 0 & 1 & 0 & 0 & 0 & 0 & -1.0 & 0 \\
\hline$\pi_{5}$ & 0 & 0 & 0 & 0 & 1 & 0 & 0 & 0 & -1.0 & 0 \\
\hline$\pi_{6}$ & 0 & 0 & 0 & 0 & 0 & 1 & 0 & 0 & -1.0 & 0 \\
\hline$\pi_{7}$ & 0 & 0 & 0 & 0 & 0 & 0 & 1 & 0 & -1.0 & 0 \\
\hline$\pi_{8}$ & 0 & 0 & 0 & 0 & 0 & 0 & 0 & 1 & -1.0 & 0 \\
\hline
\end{tabular}

\section{Statistical methodology for calibration and validation of the derived models}

During validation, the model configuration was obtained for the calibration and it was used to test for different geometrics and flow conditions looking for a low value for RMSE, the response variable. Similarly, during the calibration half of the experimental data were set to their coefficients, and the remaining set of data was equally be used for 
verification purposes. Using about thirty out of the fifty data sets generated in the laboratory-based on regression analysis, regression analysis was applied to the non-linear model to determine the constants The line of best was be judged using the Spearman Pearson's Coefficient of Correlation. The remaining twenty data sets from laboratory experiments were used for verification of the model. Additionally, the lack of the fittest was used also to verify the order of the suggested regression model using the water depth as the response variable. Several statistical indexes were used from the experimental work to evaluate the predictions obtained by numerical models the root mean square error (RMSE) being one of the most widely used for calibration and validation, for the case of water depths in horizontal channels. The RMSE error will be computed using this equation,

$\operatorname{RMSE}=\left[\frac{1}{N} \sum_{i=1}^{N}\left(Q_{i}-P_{i}\right) 2\right] 0.5$

Where $\mathrm{N}$ is the quantity of information, Qi is the observed (measured) values of the response variable and $\mathrm{P}_{\mathrm{i}}$ is the Predicted value of the answer variable.

\subsection{Presentation of experimental data}

Table 3 Experimental data for upstream and downstream weirs

\begin{tabular}{|c|c|c|c|c|c|c|c|c|c|c|c|c|}
\hline \multicolumn{6}{|c|}{ Upstream of Weir } & \multicolumn{3}{|c|}{$\begin{array}{l}\text { Upstream } \\
\text { Hydraulic Jump }\end{array}$} & \multicolumn{4}{|c|}{$\begin{array}{l}\text { Downstream } \\
\text { Hydraulic Jump }\end{array}$} \\
\hline 1 & 2 & 3 & 4 & 5 & 6 & 7 & 8 & 9 & 10 & 11 & 12 & 13 \\
\hline Flow & $\begin{array}{l}\text { Run } \\
\text { No. }\end{array}$ & $\begin{array}{l}\mathrm{Z} \\
(\mathrm{m})\end{array}$ & $\begin{array}{l}\text { Y1 } \\
\text { (m) }\end{array}$ & $\begin{array}{l}\mathrm{V} 1 \\
(\mathrm{~m} / \mathrm{s})\end{array}$ & $\begin{array}{l}\mathrm{Q}_{1} \times 10^{-4} \\
\left(\mathrm{~m}^{3} / \mathrm{s}\right)\end{array}$ & $\begin{array}{l}\mathrm{Y} 2 \\
(\mathrm{~m})\end{array}$ & $\begin{array}{l}\mathrm{V} 2 \\
(\mathrm{~m} / \mathrm{s})\end{array}$ & $\begin{array}{l}\mathrm{Q}_{2} \\
\mathrm{x} 10^{-4} \\
\left(\mathrm{~m}^{3} / \mathrm{s}\right)\end{array}$ & $\begin{array}{l}\text { Y3 } \\
\text { (m) }\end{array}$ & $\begin{array}{l}\text { V3 } \\
(\mathrm{m} / \mathrm{s})\end{array}$ & $\begin{array}{l}\mathrm{Q}_{3} \mathrm{x} \\
10^{-4} \\
\left(\mathrm{~m}^{3} / \mathrm{s}\right)\end{array}$ & $\begin{array}{l}\mathrm{Dj} \\
(\mathrm{mm})\end{array}$ \\
\hline \multirow{3}{*}{$F_{1}$} & $\mathrm{~A} 01 \mathrm{X}$ & 0.025 & 0.047 & 0.13 & 4.64 & 0.007 & 0.88 & 4.60 & 0.030 & 0.20 & 4.61 & 0.50 \\
\hline & B02Y & 0.050 & 0.073 & 0.08 & 4.38 & 0.008 & 0.73 & 4.38 & 0.026 & 0.23 & 4.31 & 0.70 \\
\hline & C03Z & 0.075 & 0.099 & 0.064 & 4.76 & 0.007 & 0.90 & 4.67 & 0.031 & 0.21 & 4.73 & 0.90 \\
\hline & & & & & & & & & & & & \\
\hline \multirow{3}{*}{$F_{2}$} & $\mathrm{~A} 21 \mathrm{X}$ & 0.025 & 0.047 & 0.13 & 4.62 & 0.009 & 0.69 & 4.64 & 0.025 & 0.25 & 4.63 & 0.55 \\
\hline & $\mathrm{B} 22 \mathrm{Y}$ & 0.050 & 0.073 & 0.08 & 4.73 & 0.008 & 0.76 & 4.60 & 0.027 & 0.23 & 4.65 & 0.70 \\
\hline & $\mathrm{C} 23 \mathrm{Z}$ & 0.075 & 0.099 & 0.06 & 4.55 & 0.009 & 0.68 & 4.65 & 0.024 & 0.25 & 4.41 & 0.90 \\
\hline \multirow{4}{*}{$F_{3}$} & & & & & & & & & & & & \\
\hline & A31X & 0.025 & 0.054 & 0.17 & 6.89 & 0.013 & 0.69 & 6.72 & 0.029 & 0.30 & 6.52 & 0.70 \\
\hline & B32Y & 0.050 & 0.081 & 0.11 & 6.68 & 0.013 & 0.69 & 6.72 & 0.029 & 0.30 & 6.52 & 1.35 \\
\hline & C33Z & 0.075 & 0.106 & 0.09 & 6.72 & 0.013 & 0.69 & 6.73 & 0.031 & 0.30 & 6.74 & 1.35 \\
\hline & & & & & & & & & & & & \\
\hline \multirow{3}{*}{$F_{4}$} & $\mathrm{~A} 41 \mathrm{X}$ & 0.025 & 0.053 & 0.17 & 6.76 & 0.013 & 0.75 & 7.32 & 0.033 & 0.30 & 7.22 & 0.70 \\
\hline & B42Y & 0.050 & 0.081 & 0.11 & 6.68 & 0.012 & 0.81 & 7.29 & 0.034 & 0.28 & 7.14 & 1.30 \\
\hline & C43Z & 0.075 & 0.106 & 0.09 & 7.16 & 0.012 & 0.82 & 7.38 & 0.035 & 0.28 & 7.35 & 1.56 \\
\hline \multirow{4}{*}{$F_{5}$} & & & & & & & & & & & & \\
\hline & A51X & 0.025 & 0.053 & 0.17 & 6.63 & 0.013 & 0.89 & 8.63 & 0.040 & 0.29 & 8.64 & 0.75 \\
\hline & B52Y & 0.050 & 0.082 & 0.11 & 6.76 & 0.012 & 0.90 & 8.10 & 0.038 & 0.28 & 8.20 & 1.33 \\
\hline & C53Z & 0.075 & 0.105 & 0.10 & 8.62 & 0.012 & 0.96 & 8.64 & 0.041 & 0.28 & 8.61 & 1.55 \\
\hline
\end{tabular}


Table 4 Alternate, conjugate, and critical flow depths measurement

\begin{tabular}{|c|c|c|c|c|c|c|c|c|c|}
\hline \multirow[b]{2}{*}{ Flow } & \multirow[b]{2}{*}{$\begin{array}{l}\text { No of } \\
\text { Tablets }\end{array}$} & \multicolumn{2}{|c|}{ Conjugate Depths } & \multicolumn{2}{|c|}{ Alternate Depths } & \multicolumn{4}{|c|}{ Critical Depth } \\
\hline & & $\begin{array}{l}y_{2} \\
(\mathrm{~m})\end{array}$ & $\begin{array}{l}y_{3} \\
(\mathrm{~m})\end{array}$ & $\begin{array}{l}y_{2}^{\prime} \\
(\mathrm{m})\end{array}$ & $\begin{array}{c}y_{3}^{\prime} \\
(\mathrm{m})\end{array}$ & $\begin{array}{l}y_{o} \\
(\mathrm{~m})\end{array}$ & $\begin{array}{l}y_{c, c a l} \\
(\mathrm{~m})\end{array}$ & $\begin{array}{l}y_{c, \text { theory }} \\
\text { (m) }\end{array}$ & $\begin{array}{l}y_{c} \\
(\mathrm{~m})\end{array}$ \\
\hline \multirow{3}{*}{$F_{1}$} & $1 \mathrm{~A}$ & 0.007 & 0.030 & 0.045 & 0.010 & 0.022 & 0.015 & 0.015 & 0.016 \\
\hline & $2 \mathrm{~B}$ & 0.008 & 0.026 & 0.034 & 0.010 & 0.023 & 0.015 & 0.015 & 0.016 \\
\hline & $3 \mathrm{C}$ & 0.007 & 0.031 & 0.046 & 0.008 & 0.024 & 0.016 & 0.016 & 0.016 \\
\hline & & & & & & & & & \\
\hline \multirow{3}{*}{$F_{2}$} & $1 \mathrm{~A} 1$ & 0.009 & 0.025 & 0.031 & 0.011 & 0.022 & 0.015 & 0.018 & 0.018 \\
\hline & 2B1 & 0.008 & 0.027 & 0.036 & 0.010 & 0.023 & 0.015 & 0.016 & 0.017 \\
\hline & $3 \mathrm{C} 1$ & 0.009 & 0.024 & 0.031 & 0.009 & 0.024 & 0.016 & 0.016 & 0.016 \\
\hline & & & & & & & & & \\
\hline \multirow{3}{*}{$F_{3}$} & $1 \mathrm{~A} 2$ & 0.013 & 0.029 & 0.034 & 0.015 & 0.029 & 0.019 & 0.020 & 0.020 \\
\hline & 2B2 & 0.013 & 0.029 & 0.034 & 0.015 & 0.031 & 0.021 & 0.020 & 0.021 \\
\hline & $3 \mathrm{C} 3$ & 0.013 & 0.031 & 0.034 & 0.015 & 0.031 & 0.021 & 0.021 & 0.021 \\
\hline & & & & & & & & & \\
\hline \multirow{3}{*}{$F_{4}$} & $1 \mathrm{~A} 3$ & 0.013 & 0.033 & 0.038 & 0.015 & 0.028 & 0.018 & 0.020 & 0.020 \\
\hline & 2B3 & 0.012 & 0.034 & 0.042 & 0.014 & 0.031 & 0.021 & 0.020 & 0.021 \\
\hline & $3 \mathrm{C} 3$ & 0.012 & 0.035 & 0.044 & 0.014 & 0.051 & 0.034 & 0.021 & 0.021 \\
\hline & & & & & & & & & \\
\hline \multirow{3}{*}{$F_{5}$} & $1 \mathrm{~A} 4$ & 0.013 & 0.040 & 0.057 & 0.014 & 0.028 & 0.018 & 0.019 & 0.020 \\
\hline & 2B4 & 0.012 & 0.038 & 0.051 & 0.011 & 0.032 & 0.021 & 0.020 & 0.021 \\
\hline & $3 \mathrm{C} 4$ & 0.012 & 0.041 & 0.057 & 0.015 & 0.030 & 0.020 & 0.021 & 0.021 \\
\hline
\end{tabular}

Table 5 The Energy Head Loss due to the Hydraulic Jump.

\section{Experimental work}

\begin{tabular}{|c|c|c|c|c|c|c|c|}
\hline Flow & $\begin{array}{l}\text { No of } \\
\text { Tablets }\end{array}$ & $\begin{array}{r}E_{2} \\
(\mathrm{~m})\end{array}$ & $(\mathrm{m}){ }^{E_{3}}$ & $\begin{array}{l}\Delta \mathrm{E} \\
(\mathrm{m})\end{array}$ & $\begin{array}{l}E_{2}^{\prime} \\
\text { (m) }\end{array}$ & (m) ${ }^{E_{3}^{\prime}}$ & $\begin{array}{l}\Delta \mathrm{E}^{\prime} \\
(\mathrm{m})\end{array}$ \\
\hline \multirow{3}{*}{$F_{1}$} & 1A5 & 0.046 & 0.032 & 0.013 & 0.046 & 0.032 & 0.013 \\
\hline & 2B5 & 0.035 & 0.028 & 0.006 & 0.035 & 0.028 & 0.006 \\
\hline & $3 \mathrm{C} 5$ & 0.047 & 0.032 & 0.014 & 0.047 & 0.032 & 0.014 \\
\hline \multirow{3}{*}{$F_{2}$} & $1 \mathrm{~A} 6$ & 0033 & 0028 & 0005 & 0033 & 0028 & 0005 \\
\hline & $2 \mathrm{~B} 6$ & 0.038 & 0.030 & 0.008 & 0.038 & 0.030 & 0.008 \\
\hline & $3 \mathrm{C6}$ & 0.033 & 0.027 & 0.004 & 0.033 & 0.027 & 0.004 \\
\hline \multirow{4}{*}{$F_{3}$} & & & & & & & \\
\hline & 1A7 & 0.037 & 0.034 & 0.003 & 0.037 & 0.034 & 0.003 \\
\hline & 2B7 & 0.037 & 0.034 & 0.003 & 0.037 & 0.034 & 0.003 \\
\hline & $3 \mathrm{C} 7$ & 0.040 & 0.036 & 0.004 & 0.040 & 0.036 & 0.004 \\
\hline & & & & & & & \\
\hline \multirow{3}{*}{$F_{4}$} & $1 \mathrm{~A} 8$ & 0.042 & 0.034 & 0.004 & 0.042 & 0.034 & 0.004 \\
\hline & 2B8 & 0.045 & 0.038 & 0.007 & 0.045 & 0.038 & 0.007 \\
\hline & 3C8 & 0.045 & 0.038 & 0.007 & 0.045 & 0.038 & 0.007 \\
\hline & & & & & & & \\
\hline \multirow{3}{*}{$F_{5}$} & $1 \mathrm{~A} 9$ & 0.052 & 0.044 & 0.009 & 0.052 & 0.044 & 0.009 \\
\hline & 2B9 & 0.053 & 0.042 & 0.010 & 0.053 & 0.042 & 0.010 \\
\hline & 3B10 & 0.059 & 0.045 & 0.012 & 0.059 & 0.045 & 0.012 \\
\hline
\end{tabular}




\section{Results and discussion}

\subsection{The relationship between sequent depth ratio and velocity ratio}

From the experimental work and theoretical analyses carried out, and the results presented from Table 3 to 6: There was continuity of flow in the open channel. Also, the distance between the weir and the jump (Dj) is directly proportional to the discharge rate of weir overflow and weir height (Z). Similarly, the upstream of the weir, the Froude numbers range from 0.09 to $0.24\left(0.09<\mathrm{Fr}_{3}<0.24\right)$, showing that the flows are subcritical. At the pre-hydraulic jump section, the Froude numbers range from 1.90 to $4.10\left(1.90<\operatorname{Fr}_{1}<4.10\right)$, which indicates that the flow conditions are supercritical and the jumps vary from weak to oscillating. The Froude numbers obtained from the post-hydraulic jump section of the range 0.33 to $0.56\left(0.3<\mathrm{Fr}_{2}<0.56\right)$, also reveal that the flows are subcritical.

Table 6 The range of the Froude boundary conditions

\begin{tabular}{|c|c|c|c|c|c|c|c|c|}
\hline Flow & $\begin{array}{l}\text { No of } \\
\text { Tablets } \\
\end{array}$ & $\mathbf{F}_{\mathrm{r} 1}$ & $\mathbf{F}_{\mathrm{r} 2}$ & $F_{r 3}$ & $\frac{y_{3}}{y_{2}}$ & $\frac{v_{2}}{v_{3}}$ & \multicolumn{2}{|l|}{ Boundaries } \\
\hline \multirow{3}{*}{$F_{1}$} & 1 & 0.19 & 3.34 & 0.38 & 4.26 & 4.26 & \multirow{3}{*}{$\begin{array}{l}\mathrm{F}_{\mathrm{r}}>1 \\
\text { Supercritical } \\
\text { Flow }\end{array}$} & \multirow{3}{*}{$\begin{array}{l}\mathrm{F}_{\mathrm{r}}=1-1.7 \\
\text { undular jump }\end{array}$} \\
\hline & 2 & 0.09 & 2.61 & 0.45 & 3.22 & 3.22 & & \\
\hline & 3 & 0.065 & 3.43 & 0.38 & 4.42 & 4.33 & & \\
\hline \multirow{3}{*}{$F_{2}$} & 1 & 0.23 & 2.31 & 0.49 & 2.81 & 2.81 & \multirow{3}{*}{$\begin{array}{l}\mathrm{F}_{\mathrm{r}}=1 \\
\text { Critical } \\
\text { Flow }\end{array}$} & \multirow{3}{*}{$\begin{array}{l}F_{r}=1.7-2.5 \\
\text { weak jump }\end{array}$} \\
\hline & 2 & 0.09 & 2.75 & 0.45 & 3.40 & 3.40 & & \\
\hline & 3 & 0.07 & 2.29 & 0.52 & 2.66 & 2.66 & & \\
\hline \multirow{3}{*}{$F_{3}$} & 1 & 0.23 & 1.93 & 0.56 & 2.23 & 2.23 & \multirow{3}{*}{$\begin{array}{l}\mathrm{F}_{\mathrm{r}}<1 \\
\text { Subcritical } \\
\text { Flow }\end{array}$} & \multirow{3}{*}{$\begin{array}{l}\mathrm{F}_{\mathrm{r}}=2.5-45 \\
\text { oscillating jump }\end{array}$} \\
\hline & 2 & 0.12 & 1.93 & 0.56 & 2.23 & 2.23 & & \\
\hline & 3 & 0.09 & 2.04 & 0.54 & 2.38 & 2.38 & & \\
\hline \multirow{3}{*}{$F_{4}$} & 1 & 0.23 & 2.10 & 0.53 & 2.56 & 2.56 & & \multirow{3}{*}{$\begin{array}{l}\mathrm{F}_{\mathrm{r}}=4.5-9.0 \\
\text { steady jump }\end{array}$} \\
\hline & 2 & 0.12 & 2.36 & 0.48 & 2.83 & 2.83 & & \\
\hline & 3 & 0.09 & 2.39 & 0.48 & 2.92 & 2.92 & & \\
\hline \multirow[t]{3}{*}{$F_{5}$} & 1 & 0.23 & 2.48 & 0.48 & 3.04 & 3.04 & & \multirow{3}{*}{$\begin{array}{l}\mathrm{F}_{\mathrm{r}}>9.0 \\
\text { Strong jump }\end{array}$} \\
\hline & 2 & 0.12 & 2.62 & 0.46 & 3.16 & 3.16 & & \\
\hline & 3 & 0.09 & 2.80 & 0.44 & 3.41 & 3.41 & & \\
\hline
\end{tabular}

This clearly, demonstrates that for a hydraulic jump to occurs in an open channel only when a flowing liquid transit from unstable, supercritical, or rapid flow to stable, subcritical or tranquil flow. The inflow Froude number Fr of a hydraulic jump is proportional to the sequent depth ratio as well as post and pre-hydraulic jump sections of pre and post-hydraulic jump sections, irrespective of what causes the jump. Table 6 benchmarked the relationship between sequent depth ratio and velocity ratio as $\frac{y_{3}}{y_{2}}=\frac{v_{2}}{v_{3}}=-0.5024+1.485 \mathrm{~F}_{\mathrm{r} 2}$ with $\mathrm{R}^{2}=0.9957$

\subsection{The Effect of Length of jump against Depth of flow}

Table 6 compares the Froude numbers obtained, at the upstream of the weir, the Froude numbers range from 0.09 to $0.23\left(0.09<\mathrm{F}_{\mathrm{r} 1}<0.23\right)$, showing that the flows are subcritical. At the pre-hydraulic jump section, the Froude numbers range from 1.93 to $3.34\left(1.93<\mathrm{F}_{\mathrm{r} 2}<3.34\right)$, showing that the flows there are supercritical and the jumps vary from weak to oscillating. The Froude numbers obtained from the post-hydraulic jump section range from 0.38 to $0.56\left(0.38<\mathrm{F}_{\mathrm{r} 3}<\right.$ 0.56), also showing that the flows are subcritical. This proves that hydraulic jump occurs in an open channel when a flowing liquid transits from unstable, supercritical, or rapid flow to stable, subcritical, or tranquil one.

\subsection{Influence of weir drop height on the slope of the channel}

Similarly, for the predicted sequent depth ratio (D) values are plotted against the observed ones. These are shown in Figures 6 to 20. Similarly, from the graphs and tables, its performance of the prediction equation can be taken as quite satisfactory. From the plotted graphs, it demonstrates that for weir drop height, $\Delta \mathrm{z}=4.5 \mathrm{~cm}$, predicted sequent depth 
(D) slightly differs from the observed D. for $\Delta \mathrm{z}=6 \mathrm{~cm}$, the equation slightly overestimates the sequent depth ratio. This may be the cause of a slight mismatch of results with the experimental data. More so, the weir drop height, $\Delta \mathrm{z}=2 \mathrm{~cm}$ predicted value of D matches with the observed values in a satisfactory manner. However, for these cases plotted points lie above and below the line of perfect agreement acceptably. Similarly, for all weir drop heights with different channel slopes, the percentage deviation varies from the actual data varies from $-30.00 \%$ to $+30.00 \%$, as shown from Figures 6 to 20 respectively.

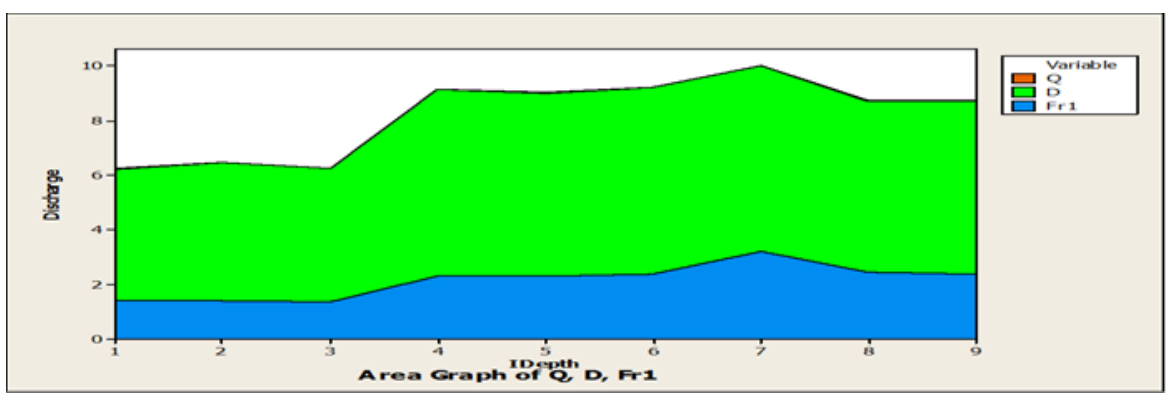

Figure 6 Comparison between predicted D and observed D with drop height, $\Delta \mathrm{z} 4.5 \mathrm{~cm}$; (a) Slope $=0.000$

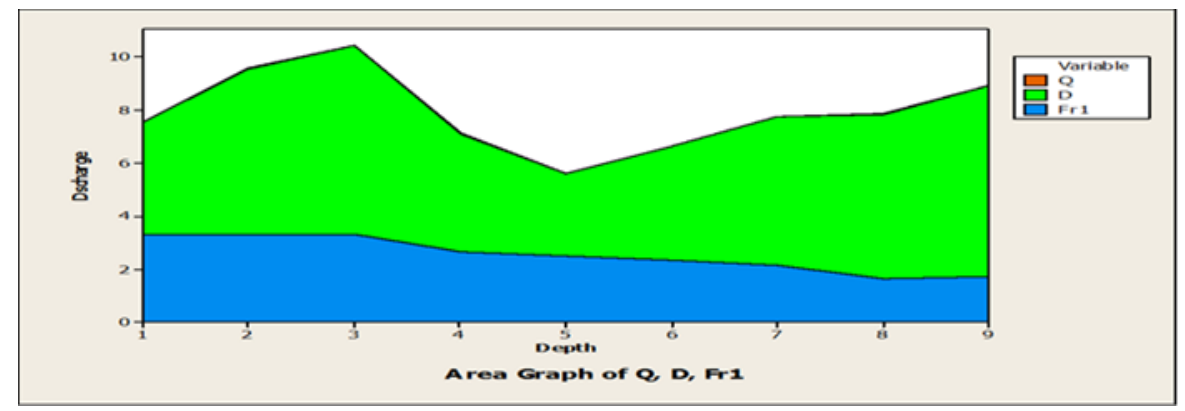

Figure 7 Comparison between predicted D and observed D with drop height, $\Delta \mathrm{z} 4.5 \mathrm{~cm}$; (a) Slope $=0.000$

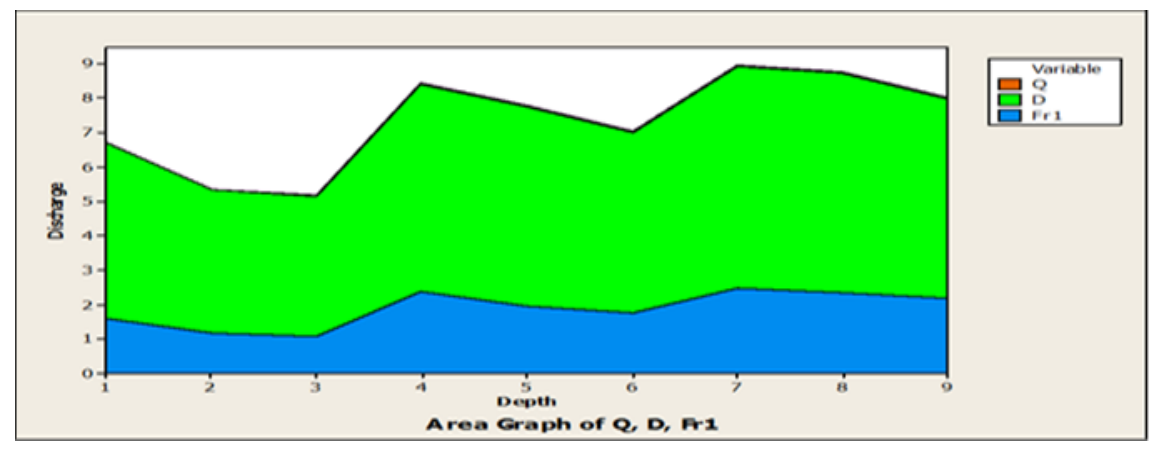

Figure 8 Comparison between predicted D and observed D with drop height, $\Delta \mathrm{z} 4.5 \mathrm{~cm}$; (a) Slope $=0.000$ 


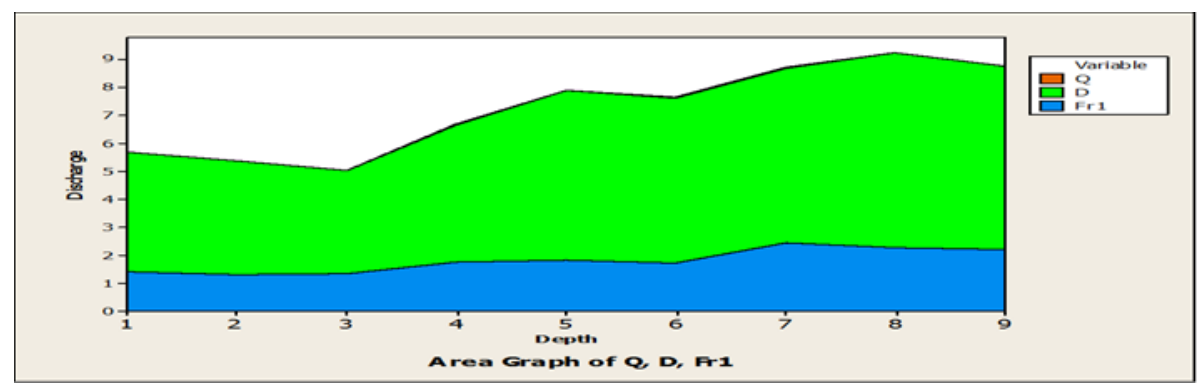

Figure 9 Comparison between predicted D and observed D with drop height, $\Delta \mathrm{z} 4.5 \mathrm{~cm}$; (a) Slope $=0.000$

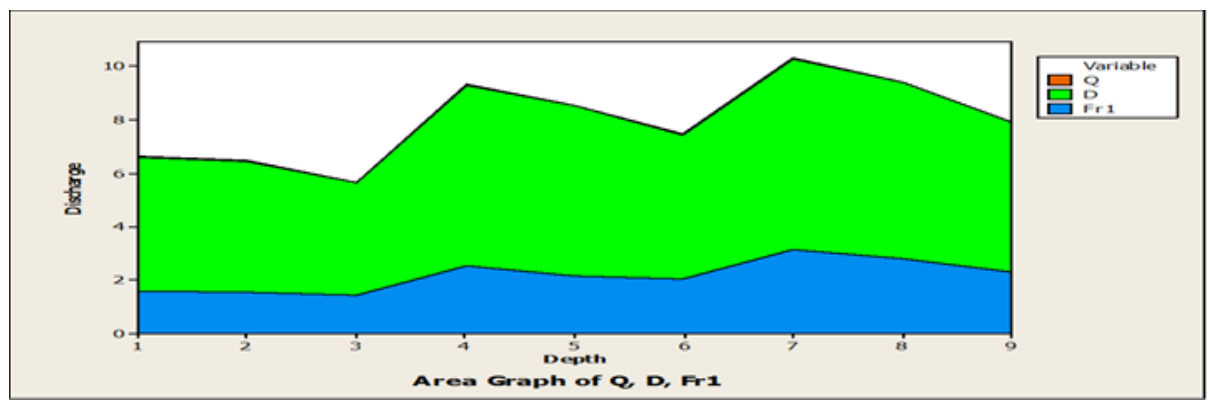

Figure 10 Comparison between predicted D and observed D with drop height, $\Delta \mathrm{z} 4.5 \mathrm{~cm}$; (a) Slope $=0.000$.

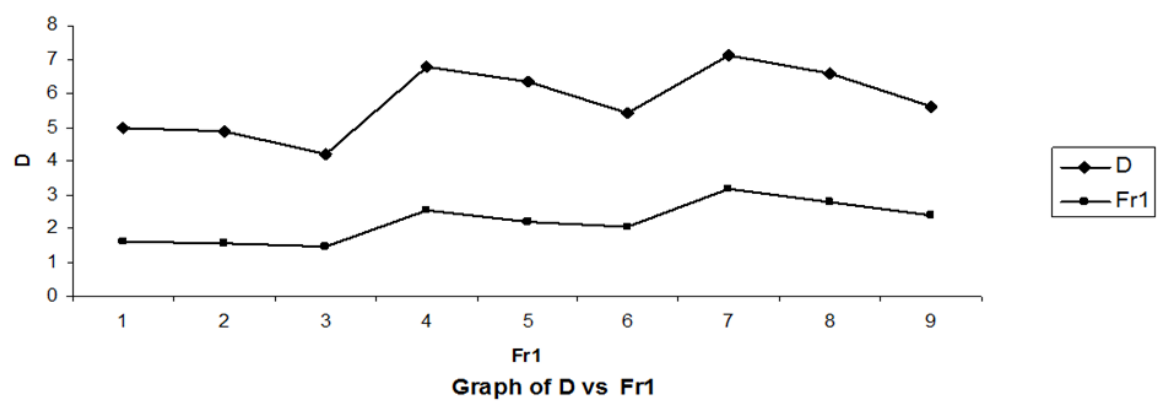

Figure 11 Comparison between predicted D and observed D with drop height, $\Delta \mathrm{z} 4.5 \mathrm{~cm}$; (a) Slope $=0.000$

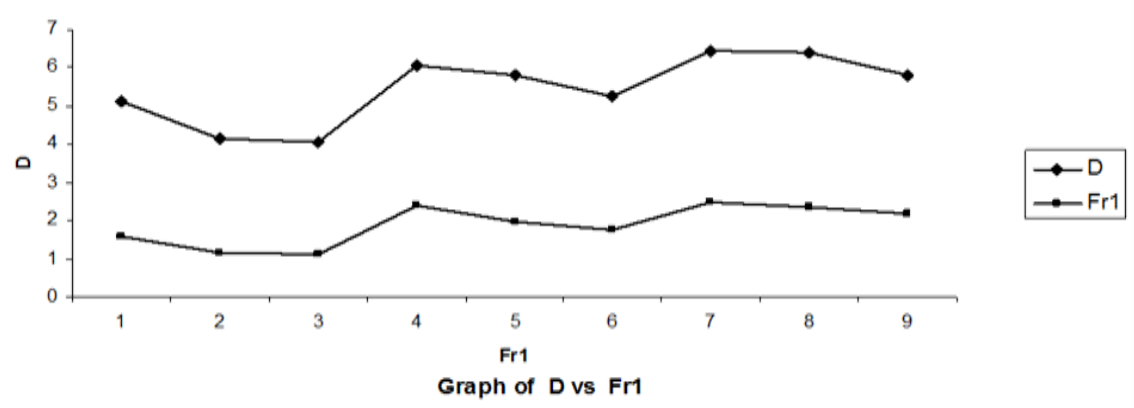

Figure 12 Comparison between predicted D and observed D with drop height, $\Delta \mathrm{z} 4.5 \mathrm{~cm}$; (a) Slope $=0.000$ 


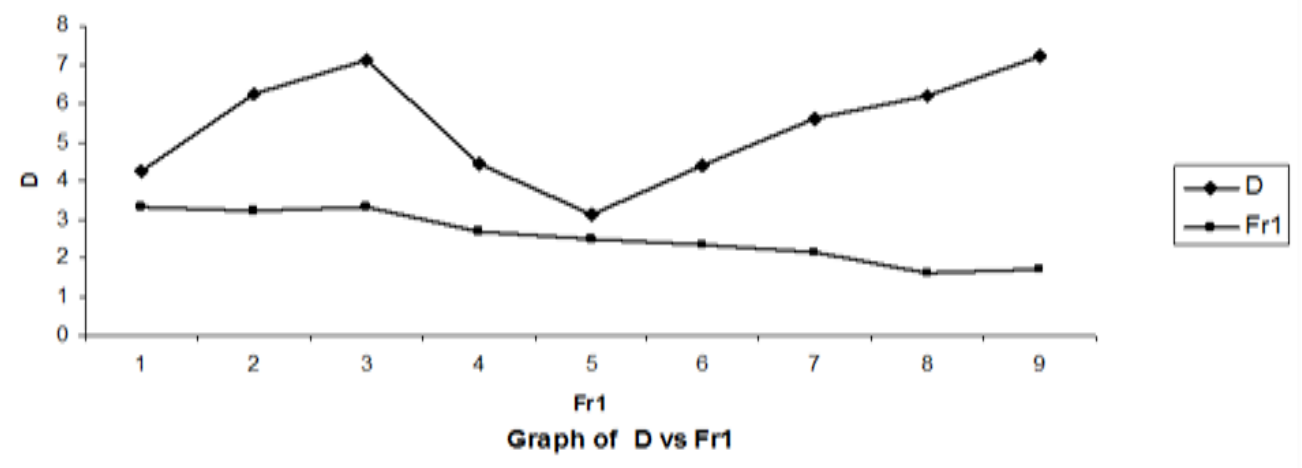

Figure 13 Comparison between predicted D and observed D with drop height, $\Delta \mathrm{z} 4.5 \mathrm{~cm}$; (a) Slope $=0.000$

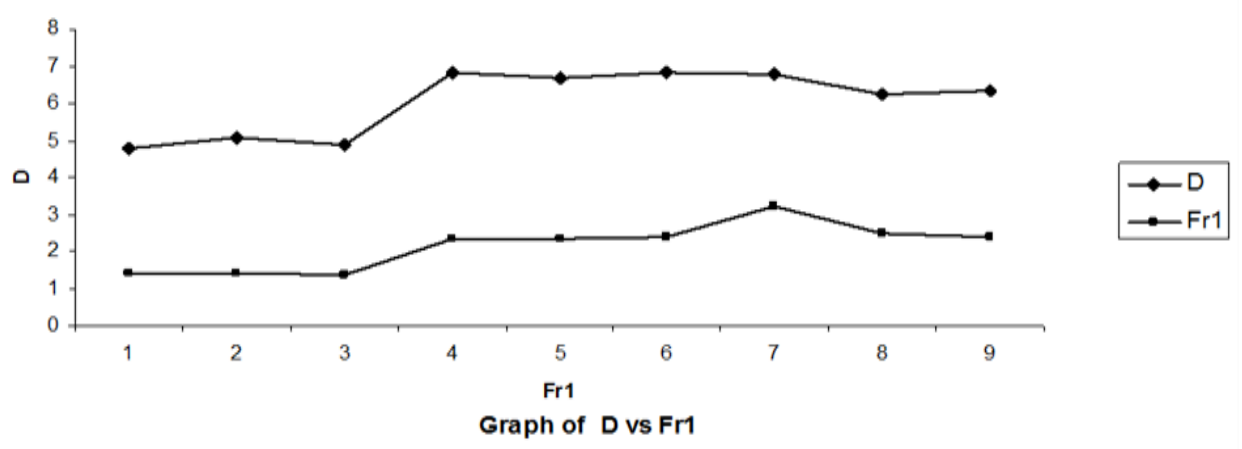

Figure 14 Comparison between predicted D and observed D with drop height, $\Delta \mathrm{z} 4.5 \mathrm{~cm}$; (a) Slope $=0.000$

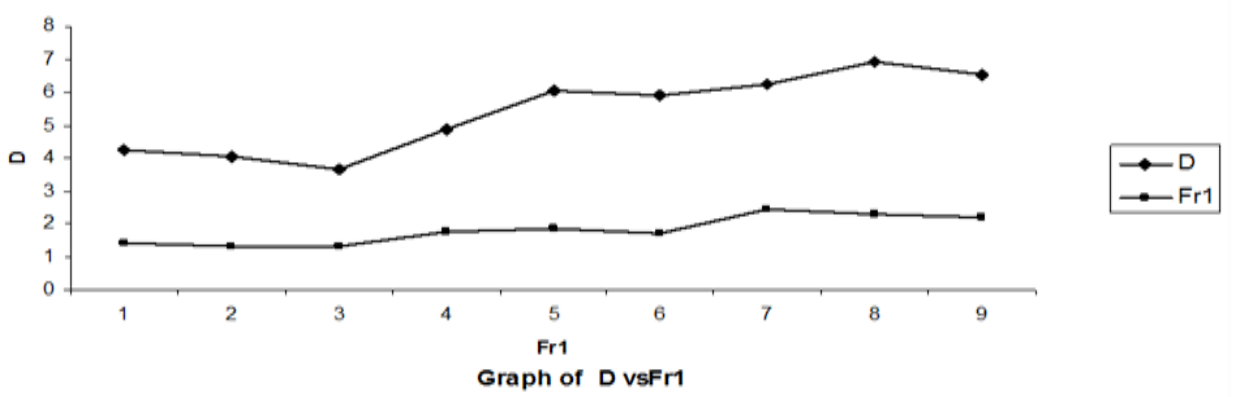

Figure 15 Comparison between predicted D and observed D with drop height, $\Delta \mathrm{z} 4.5 \mathrm{~cm}$; (a) Slope $=0.000$ 


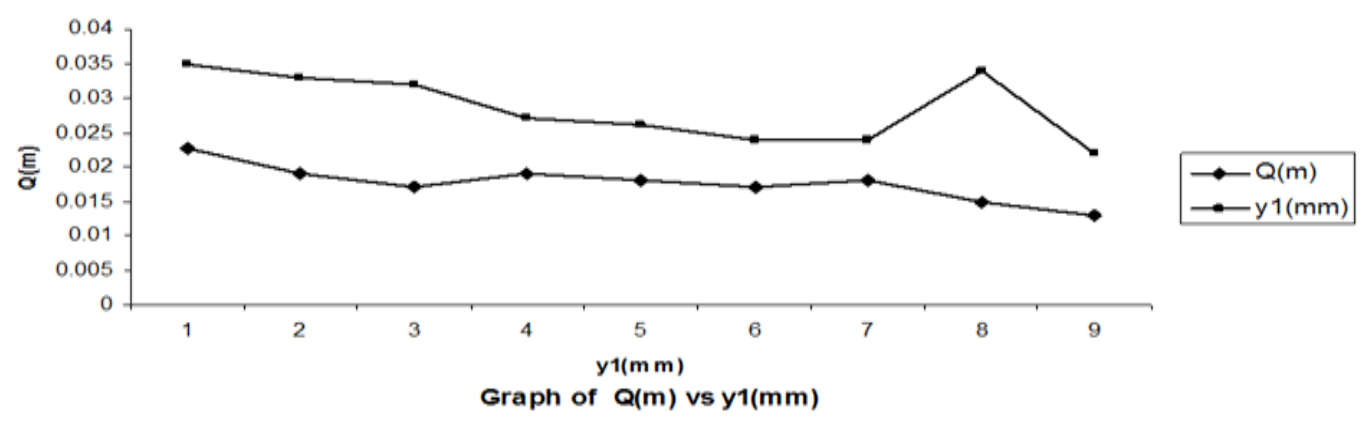

Figure 16 Comparison between predicted D and observed D with drop height, $\Delta \mathrm{z} \quad 4.5 \mathrm{~cm}$; (a) Slope $=0.000$

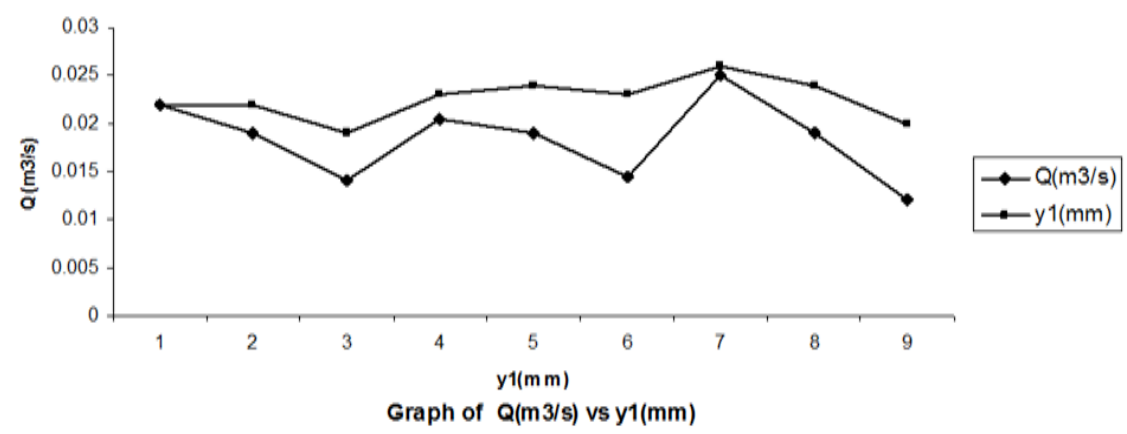

Figure 17 Comparison between predicted D and observed D with drop height, $\Delta \mathrm{z} 4.5 \mathrm{~cm}$; (a) Slope $=0.000$

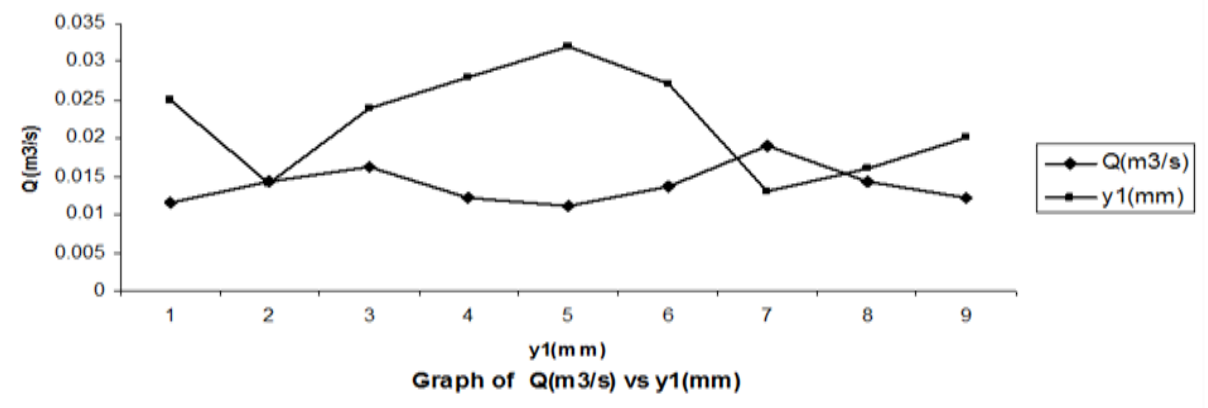

Figure 18 Comparison between predicted D and observed D with drop height, $\Delta \mathrm{z} 4.5 \mathrm{~cm}$; (a) Slope $=0.000$ 


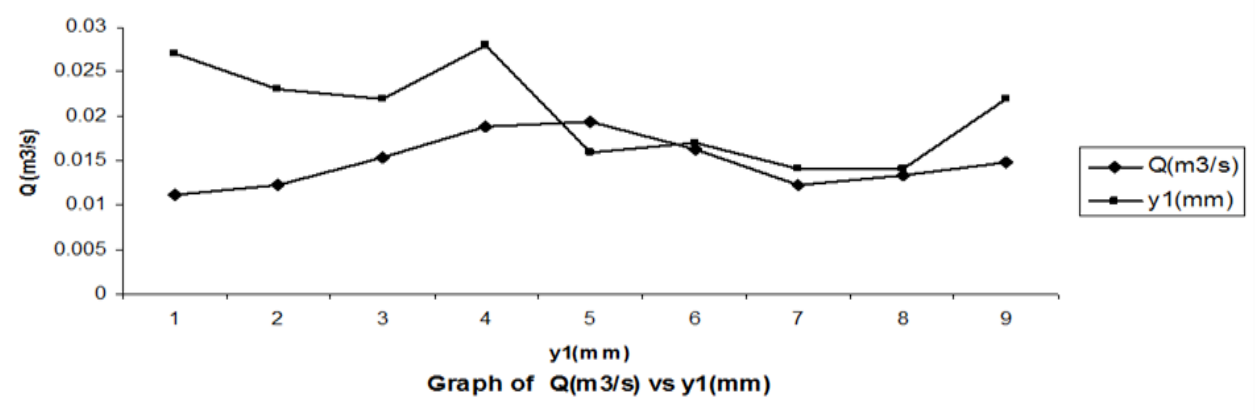

Figure 19 Comparison between predicted D and observed D with drop height, $\Delta \mathrm{z} 4.5 \mathrm{~cm}$; (a) Slope $=0.000$

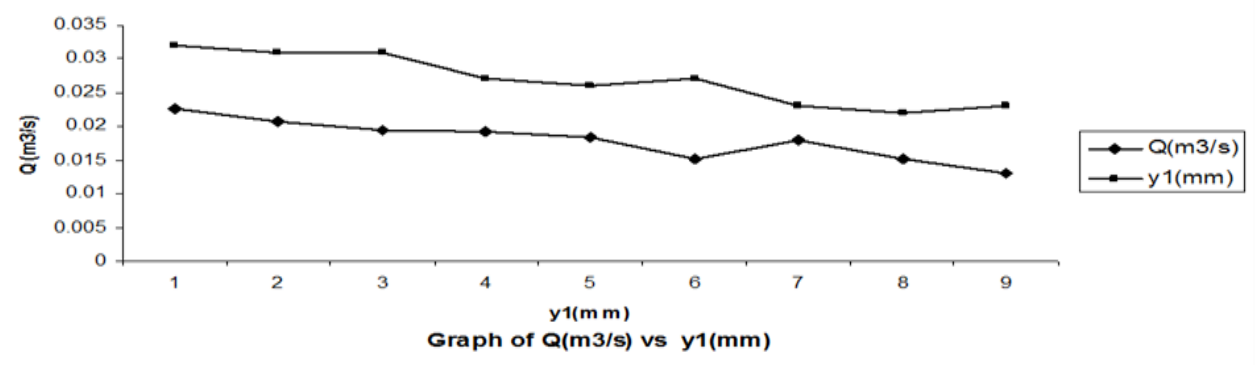

Figure 20 Comparison between observed D with weir drop height, $\Delta \mathrm{z}$

\section{Conclusion}

We carried out a series of hydraulic experiments in a variable slope open channel hydraulic (VSOCH) from the Civil Engineering Department of Water and hydraulics laboratory of the Cross River University of Technology in Calabar, to propose an improved condition to decide the water-powered bounce length of various water streams with a discretionary increment and abatement, a movable entryway opening and slants. The current work additionally shows $\mathrm{R}^{2}=0.9997$, The outcomes exhibit that the two conditions are energetically prescribed to assess L in rectangular open direct hydraulic jump as appeared in Figure 5 and the proposed design in Figure 2. Following the laboratory experimental work, theoretical framework and analyses carried out in the open flow channel modeling of the hydraulic jump the conclusions were drowned as follows: From the viewpoint of the weir, the energy loss due to the hydraulic jump range between $0.013-0.020$. Similarly, the upstream of the weir, the Froude numbers between the range of 0.068 to $0.090\left(0.068<\mathrm{Fr}_{1}<0.09\right)$, indicating that the flows were subcritical. The Froude numbers from the post-hydraulic jump section between $0.37-0.41\left(0.37<\mathrm{Fr}_{3}<0.41\right)$, also indicating that the flows are subcritical. The Froude numbers from the post-hydraulic jump section within 0.37 to $0.41\left(0.37<\mathrm{Fr}_{3}<0.41\right)$, this shows that the flows are subcritical. The relationship between sequent depth ratio $\mathrm{y}_{3} / \mathrm{y}_{2}$ and velocity ratio $\mathrm{v}_{2} / \mathrm{v}_{3}$ is approximately $-5024+1.485 \mathrm{Fr}_{2}$ with $\mathrm{R}^{2}$ $=0.9957$ indicating that as the sequent depth ratio and velocity ratio increases the inflow Froude number Fr 2 also increases. Accordingly, the level-bedded constricted flume, the energy loss due to hydraulic jump ranged from - 0.001 to 0.001 which shows some energy gain with an increase in the rate of discharge through the flume. The upstream of the flume, the Froude numbers range from 0.038 to $0.052\left(0.038<\mathrm{Fr}_{1}<0.52\right)$, showing that the flows were subcritical. From the experiment, theory, and analyses done, the following conclusions are obtained. There was continuity of flow in the open channel. Also, the distance between the weir and jump $\left(d_{j}\right)$ is proportional to the discharge rate of weir overflow and weir height (Z). The energy loss range due to the hydraulic jump is $0.003-0.028$. Upstream of the weir, the Froude numbers range from 0.09 to $0.24\left(0.09<\mathrm{F}_{\mathrm{r} 3}<0.24\right)$, showing that the flows are subcritical. At the pre-hydraulic jump section, the Froude numbers range from 1.90 to $4.10\left(1.90<\mathrm{F}_{\mathrm{r} 1}<4.10\right)$, showing that the flows there are supercritical and the jumps vary from weak to oscillating. The Froude numbers obtained from the post-hydraulic jump section range from 0.33 to $0.56\left(0.3<\mathrm{F}_{\mathrm{r} 2}<0.56\right)$, also showing that the flows are subcritical. This proves that hydraulic jump occurs in an open channel only when a flowing liquid transit from unstable, supercritical, or rapid flow to stable, subcritical or tranquil flow. The inflow Froude number $\mathrm{F}_{\mathrm{r}}$ of a hydraulic jump is proportional to the sequent depth ratio of the post and pre-hydraulic jump sections or velocity of ratio pre and post-hydraulic jump sections, irrespective of what causes the jump. 


\section{Compliance with ethical standards}

\section{Acknowledgments}

The authors sincerely appreciate the Management of Cross River University of Technology, for their financial support through the Educational Trust Fund that aided us to carry out the study successfully.

\section{Disclosure of conflict of interest}

The authors have declared that no conflict of interest.

\section{Statement of ethical approval}

'The present research work does not contain any studies performed on animals/humans subjects by any of the authors'.

\section{Statement of informed consent}

The authors have declared that no conflict in the statement of informed consent.

\section{References}

[1] EG Ewah, EE Nyah, REE. Antigha, JG. Egbe. Experimental Investigation of Energy Dissipation in Hydraulic Jump: A Comparison of Weir and Level Bedded Constricted Flume. International Journal of Engineering Trends and Technology (IJETT). July 2018; 61(1).

[2] JG Egbe, EE Nyah, SE Ubi, OO Ewa, EE Okon. Correlation between critical overflow, depth ratio, and Froude number in broad-crested weir. Asian Academic Research Journal of Multidisciplinary. 2018; 5(7): 1-9.

[3] Rajaratnam N. Hydraulic Jumps, Chapter 4, Advances in Hydroscience, ed Yen Te Chow. 1967; 4: 198-280.

[4] Darcy HPG, Bazin H. Recherches hydrauliques (Hydraulic research), Imprimerie Impériales, Paris, 1ère et 2ème Parties in French. 1985.

[5] Riegel RM, Beebe JC. The Hydraulic jump as a means of Dissipating Energy, Miami Conservancy District, and Technical Reports Part. 1917; 111: 60-111.

[6] Yarnell DL. Bridge piers as channel obstructions (No. 442). US Dept. of Agriculture. 1934.

[7] Hager WH, Bremen R. Classical hydraulic jump: sequent depths. Journal of Hydraulic Research. 1990.

[8] Ohtsu I, Yasuda Y, Gotoh H. Flow conditions of undular hydraulic jumps in horizontal rectangular channels. Journal of Hydraulic Engineering. 2003; 129(12), 948-955.

[9] Lopez-Egea M, Nistor I, Townsend R. An experimental study of the impact of crest width on the characteristics of downstream submerged hydraulic jumps on low-head dam structures. 1st Prize - Civil Engineering Section. Research Poster Paper Competition- Faculty of Engineering Research Day, University of Ottawa. 2014.

[10] Adam MA, R e FJ. Characteristics of B-Jump with Different Toe Locations, Journal of Hydraulic Engineering, ASCE. 1993; 119(8), 939-948.

[11] Ohtsu I, Yasuda Y, Gotoh H. Flow conditions of undular hydraulic jumps in horizontal rectangular channels. Journal of Hydraulic Engineering. 2003; 129(12): 948-955.

[12] Heidarpour M, Chamani MR. Velocity distribution over cylindrical weir Journal of Hydraulic Research. 2006; 44 (5): 708-711.

[13] Carollo FG, Ferro V, Pampalone V. Hydraulic jumps on rough beds. Journal of Hydraulic Engineering. 2007; 133(9): 989-999.

[14] Carollo FG, Ferro V, Pampalone V. Sequent depth ratio of a B-jump on smooth and rough beds. Journal of Agricultural Engineering,. 2013; XLIV (e12): 82-86.

[15] Chanson H. Current knowledge in hydraulic jumps and related phenomena. A survey of experimental results. European Journal of Mechanics - B/Fluids. 2009; 28(2): 191-210.

[16] Afzal N, Bushra A, Seena A. Analysis of turbulent hydraulic jump over a transitional rough bed of a rectangular channel: Universal relations. Journal of Engineering Mechanics. 2011; 137(12): 835-845. 
[17] Carollo FG, Ferro V, Pampalone V. Sequent depth ratio of a B-jump on smooth and rough beds. Journal of Agricultural Engineering. 2013; XLIV (e12): 82-86.

[18] JG. Egbe and JC. Agunwamba. The Proposed Design and Derivation of Mathematical Procedure for Modeling of Hydraulic Jump in a Broad Crested Weir in an Open Channel Flow. International Journal of Hydraulic Engineering 2020, 9(1): 9-14 DOI: 10.5923/j.ijhe.20200901.02.

[19] AASHTO IC. A summary of Existing Research on Low-Head Dam Removal Projects. Transportation Research Board (TRB). 2005.

[20] H Gutiérrez, R de la Vara. Análisis y diseño de experimentos, 2nd ed. Mexico City, Mexico: McGraw-Hill, 2008. 